\title{
UMA RUÍNA, DUAS HISTÓRIAS: uma breve análise sobre a pequena ruína da TekoáTavaí
}

\author{
Orestes Jayme Mega ${ }^{\top}$ \\ Email:orestes_mega@yahoo.com.br
}

\begin{abstract}
Resumo: a partir dos dados etnográficos obtidos na aldeia Mbyá-Guarani chamada TekoáTavaí, localizada no município de Cristal, estado do Rio Grande do Sul, realizouse uma análise a respeito da convivência e sobreposição de historicidades distintas intermediadas por um elemento da paisagem que serve como "símbolo material" para doisgrupos que dividem a paisagem em questão: a brasileira, e a Mbyá-Guarani. Este "símbolo material" se constitui de uma ruína de uma casa que é interpretada de diferentes maneiras a depender da perspectiva cultural. A proposta deste artigo é a de mostrar que um "símbolo material" inserido na paisagem assume tanto um caráter cívico, ligado a eventos históricos, quanto um caráter religioso relacionado a eventos míticos e, assim, pode ser integrado a duas formas diferentes de estruturas de entendimento histórico.
\end{abstract}

Palavras-chave: Mbyá-Guarani. Ruína. Historicidade.Mitologia. Paisagem.

Abstract: through ethnographic data obtained in indigenous village called Tekoá Tavaí, located in Cristal municipality, state of Rio Grande do Sul, Brazil, it was done ananalysis about the convivence and overlap of distinct history cities intermediated by an element of the landscape that works as a "material symbol" to two groups that share the landscape in question: the Brazilian and the Mbyá-Guarani. This "material symbol" is constituted of a ruin of a house that is interpreted by different manners depending on the cultural perspective. The purpose of this article is to show that a "material symbol" inserted in the land scape assumes a civic character, linked to historical events as a religious character, linked to mythical events and, this way, it can be integrated in two different forms of structures of historical understanding.

Keywords: Mbyá-Guarani. Ruin.Historicity. Mythology.Landscape.

Resumen: a partir de datos etnográficos obtenidos en el pueblo Mbyá-Guaraní llamado TekoáTavaí, ubicado en el municipio de Cristal, estado de Rio Grande do Sul, Brasil, se ha realizado un breve análisis acerca de la convivencia y superposición de historicidades distintas mediadas por un elemento del paisaje que sirve como "símbolo material" para dos grupos que dividen el paisaje en cuestión: el brasileño y el Mbyá-Guaraní. Este "símbolo material" se constituye de una ruina de una casa que se interpreta de diferentes maneras dependiendo de la perspectiva cultural. El propósito de este artículo es mostrar que un "símbolo material" insertado en el paisaje tiene tanto un carácter cívico, vinculado a acontecimientos históricos, como un carácter religioso, relacionado a los eventos míticos y por lo tanto se puede integrar en dos tipos diferentes de estructuras de comprensión histórica.

${ }^{1}$ Bacharel em arqueologia e preservação patrimonial pela UNIVASF e mestrando em antropologia pela UFPEL. Bolsista CAPES. 
Palabras-clave: Mbyá-Guarani. Ruina. Historicidad. Mitologia. Paisaje

\section{INTRODUÇÃO}

Os Mbyá-Guarani constituem um grupo indígena que habita os atuais territórios do Brasil, Paraguai, Uruguai e Argentina. No Brasil, os Mbyá-Guarani habitam, sobretudo, as regiões sul e sudeste do país (com exceção do estado de Minas Gerais), embora alguns poucos indivíduos Mbyá possam ser encontrados em outras regiões brasileiras (LITAIFF, 1996). É um grupo cujo idioma pertence à família Tupi-Guarani e que possui laços linguísticos e culturais com outras populações Guarani tais como Kaiowá e Nhandeva, embora constituam um grupo étnico independente e que possui como uma de suas principais características a mobilidade de seus membros através de suas diferentes localidades de habitação, que são conhecidas como tekoá.

O objetivo deste artigo é o de mostrar e analisar um exemplo de convivência e sobreposição de historicidades distintas intermediadas por elementos da paisagem, assim como realizar uma breve análise de um aspecto da religião Mbyá-Guarani através de um de seus símbolos que, ao estar materializado na paisagem, constitui um importante elemento para o entendimento que esta população indígena possui das relações existentes entre mitologia, paisagem, cultura material e etnicidade.

Este artigo parte da análise dos dados obtidos através de uma pesquisa etnográfica de campo realizada na TekoáTavaí ${ }^{2}$, localizada no município de Cristal, estado do Rio Grande do Sul, e cuja área está em grande parte sobreposta ao parque histórico general Bento Gonçalves, que foi criado em 1972 e que possui uma área de aproximadamente 280 hectares.A sobreposição geográfica entre este território indígena e o parque histórico dá à paisagem em questão o caráter de palimpsesto ${ }^{3}$ pois, no mesmo espaço de inscrição de uma historicidade e de uma memória pertencente a uma sociedade (a brasileira) se encontra uma outra historicidade e uma outra memória (Mbyá-Guarani).Ambas as historicidades que

${ }^{2}$ Os Mbyá-Guarani receberam a área da TekoáTavaí como mitigação aos danos causados por obras que foram realizadas nas proximidades da terra indígena que então habitavam no município de Guaíba, RS. A atual presença Mbyá na TekoáTavaí data de dezembro de 2013.

${ }^{3}$ Conforme o novo dicionário Aurélio da língua portuguesa: PALIMPSESTO: [Do grego Palímpsestos "Raspado Novamente", pelo Latim Palimpsestu] S.M. 1. Antigo material de escrita, principalmente o pergaminho, usado, em razão de sua escassez ou alto preço, duas ou três vezes (duplo palimpsesto), mediante raspagem do texto anterior. 2. Manuscrito sob cujo texto se descobre (em alguns casos a olho desarmado, mas na maioria das vezes recorrendo a técnicas especiais) a escrita ou escritas anteriores.

(C) Rev. Arqueologia Pública

\begin{tabular}{l|l|} 
Campinas, SP & v.9
\end{tabular}

No.(11)

p.157-166

suplemento

ISSN 2237-8294 
convivem na paisagem em questão estão inseridas em seus respectivos sistemas simbólicos e, desta forma, por sobre a historicidade brasileira inscreve-se (sem de forma alguma apaga-la ou ocultá-la) a historicidade Mbyá-Guarani. Desta forma, a paisagem onde se situa, simultaneamente, um importante símbolo identitário de caráter cívico, também se situa um importante símbolo identitário de caráter religioso.Em outros termos, enquanto o parque histórico general Bento Gonçalves está intimamente ligado à memória da Revolução Farroupilha e, portanto, a um evento importante da história brasileira, cujo significado se faz presente na configuração da identidade gaúcha e que se atualiza todo dia 20 de setembro (data comemorativa da Revolução Farroupilha e feriado estadual no Rio Grande do Sul ${ }^{4}$ ), a TekoáTavaí está ligada à memória Mbyá-Guarani por razões que vão da ordem das relações mito-ecológicas que esta população indígena possui com elementos da fauna e da flora presentes na mata ciliar do rio Camaquã que cruza oterritório indígena como também com a mata secundária em regenaraçãoque há na maior parte da paisagem em questão, assim como com um elemento presente na paisagem onde esta sobreposição de historicidades distintas e de símbolos diferenciados se concentra de forma especial por constituir um símbolo importante da religião Mbyá-Guarani.

O termo Tava na língua Mbyá significa ruína. Ao acrescentarmos a partícula í o termo passa para o diminutivo. Portanto, o nome que os Mbyá-Guarani escolheram para representar sua Tekoá (ruininha) está intimamente ligado à pequena ruína de uma casa presente na área e que, segundo a historicidade "oficial", seria a casa em que o general Bento Gonçalves, personagem histórico de grande importância para a história do Rio Grande do Sul, teria vivido parte de sua vida. A ruína também possui uma grande importância para os Mbyá. Segundo as informações dos Mbyá residentes em Tavaí, a pequena ruína seria uma antiga Opy, isto é, uma casa de reza onde os antigos celebravam seus ritos. Esta Opy teria sido criada pelos "jesuítas", tal como me informou meu principal interlocutor em Tavaí. Chama a atenção o fato de outras ruínas no Brasil serem consideradas por algumas populações indígenas como sendo lugares importantes para suas próprias identidades étnicas. Outro exemplo no Rio Grande do Sul é constituído pelas ruínas relacionadas às antigas missões jesuíticas localizadas no noroeste do estado. As ruínas jesuíticas são interpretadas pelos Mbyá-Guarani como sendo marcas na paisagem deixadas por um importante personagem de sua mitologia.

\footnotetext{
${ }^{4}$ A Revolução Farroupilha foi um conflito que se estendeu entre 1835 e 1845 entre as elites gaúchas e as forças imperiais. É considerado como um importante elemento da identidade cívica gaúcha.
} 
Segundo a mitologia Mbyá-Guarani, um herói mítico denominado Kesuíta vagou pelo território tradicional desta população indígena e deixou sinais de sua passagem sob a forma de ruínas (LITAIFF, 2009). Desta forma, quando os Mbyá partem em busca de novas áreas para (re)ocupar, uma das características que procuram e que tornam a área propícia é a presença de ruínas que possam ser interpretadas poreles como sinais da passagem de seus heróis míticos.

Com o mesmo valor simbólico de acidentes geográficos como rios e montanhas, para os Mbya as ruínas são memórias materializadas, monumentos que contam a história dos Guarani, demarcam o seu território, e que provam definitivamente a existência do Kesuita. (LITAIFF 2009: 145)

Ainda segundo Litaiff (2009: 145), no litoral paulista, mais precisamente no município de Itanhaém, encontra-se uma ruína de uma igreja do século XVI que foi interpretada pelos Mbyácomo sendo uma antiga casa de reza (Opy). As ruínas desta igreja são, segundo a historicidade Mbyá-Guarani, marcas materiais de um esforço de antigos xamãs que teriam se reunido no local onde hoje estão as ruínas para realizarem rituais com o propósito de alcançarem a YvyDju, uma terra mítica. Portanto, estas ruínas constituem um símbolo sagrado pois é provido de significado mitológico. Sobre símbolos sagrados é importante ter em mente que eles funcionam como pontos norteadores de visões de mundo, tal como nos lembra Geertz.

Os símbolos sagrados funcionam para sintetizar o ethos de um povo o tom, o caráter e a qualidade da sua vida, seu estilo e disposições morais e estéticos - e sua visão de mundo - o quadro que fazem do que são as coisas em suas simples atualidade, suas ideias mais abrangentes sobre ordem. Na crença e na prática religiosa, o ethos de um grupo torna-se intelectualmente razoável porque demonstra representar um tipo de vida idealmente adaptado ao estado de coisas atual que a visão de mundo descreve, enquanto esta visão de mundo torna-se emocionalmente convincente por ser apresentada como uma imagem de um estado de coisas verdadeiro, especialmente bem arrumado para acomodar tal tipo de vida. (GEERTZ1989: 66-67)

Os Mbyá-Guarani não são os únicos a relacionarem ruínas e construções antigas às suas mitologias e às suas historicidades. Dominique TilkinGallois mostra um interessante exemplo deste tipo de relação ao analisar a maneira como os Waiãpi (grupo indígena de língua tupi-guarani que habita o Amapá) reintegraram a fortaleza de São José de Macapá à sua tradição oral como sendo um lugar de grande importância para a mitologia Waiãpi. 
Em seu texto denominado Mairi Revisitada: A Reintegração da Fortaleza de Macapá na Tradição oral dos Waiãpi (1994). Dominique TilkinGallois tem como ponto de partida para sua análise um encontro do povo Waiãpi com a fortaleza de São José de Macapá, localizada na cidade de Macapá, estado do Amapá. De acordo com a mitologia Waiãpi, a fortaleza teria sido“(...) a casa de argila construída pelo herói criador lanejar e pelos primeiros homens, para se protegerem do fogo e do dilúvio que, ciclicamente, destroem a humanidade." (GALLOIS, 1994: 17).

Tal interpretação diverge da historicidade ocidental. Segundo esta forma de interpretar os eventos, a fortaleza de São José de Macapá teria sido construída no século XVIII pelos colonizadores portugueses com o propósito de defender a área da foz do rio Amazonas das intenções de outras potências coloniais. Portanto, a fortaleza de São José de Macapá seria um ponto de tensão, convivência e sobreposição de historicidades distintas e, também, o alicerce material de símbolos distintos que se situam, em parte, num polo cívico (para os brasileiros, especialmente os amapaenses), e num polo religioso (para os Waiãpi). Deste modo, pode-se dizer que a fortaleza de São José de Macapá ou, como preferem os Waiãpi, a Mairi, funciona como corporificação de sistemas simbólicos diferenciados.

Portanto, por possuírem uma ligação intensa com as mitologias de populações indígenas, tais lugares apresentados acima poderiam, segundo a definição encontrada no HandbookofNative American Mythology (BASTIAN e MITCHELL, 2004), serem considerados como lugares sagrados pois neles aconteceram eventos cuja significação vai muito além do cotidiano:

Muitos mitos falam de lugares sagrados. Estes são lugares onde eventos específicos aconteceram no passado distante e que possuem significado espiritual atual ou são lembrados porque o evento mudou a maneira como os humanos vivem ou interagem com este mundo. ${ }^{5}$ (BASTIAN e MITCHELL, 2004: 36)

Em outras palavras, nas paisagens em que estes lugares se localizam estão inscritas marcas de eventos tão importantes que, de alguma forma, representam mudanças cosmológicas fundamentais para o entendimento de mundo que estas populações indígenas possuem. No caso dos Waiãpi do Amapá, a fortaleza de São José de Macapá (Mairi) não é

\footnotetext{
5 Tradução livre do texto original: Manymythstellofsacredplaces. These are locationswherespecificeventstookplace in thedistantpastthathave spiritual meaning for todayor are remeberedbecausetheeventchangedthewayhumansliveorinteractwiththis world.
}

(C) Rev. Arqueologia Pública

\begin{tabular}{l|l} 
Campinas, SP & v.9
\end{tabular}

No.(11)

p.157-166 suplemento

ISSN 2237-8294 
apenas uma construção defensiva impressionante, mas a confirmação material de um evento mítico fundamental para a cosmologia e a religião Waiãpi e, consequentemente, para a configuração do modo-de-serWaiãpi. Para os Mbyá-Guarani, as ruínas da igreja de Itanhaém e daquelas localizadas na região das Missões (entre outras encontradas em seu território tradicional)e, no caso específico deste artigo, a ruína da terra indígena Tavaí, possuem um valor que vai muito além daquele consagrado pelos juruá (como são chamados os membros da sociedade envolvente pelos Mbyá) a estes mesmos locais. Se para os juruá estas ruínas representam as marcas materiais de eventos importantes que moldaram a história do Brasil, para os Mbyá-Guarani a importância destas mesmas ruínas é maior pois representam marcas materiais de eventos de cunho mito-cosmológico e que, portanto, moldaram não apenas a história de um país ou de uma região, mas do próprio universo tal como entendido pelos Mbyá.

Os exemplos etnográficos citados demonstram a necessidade de um aprofundamento teórico sobre o tema. Neste artigo trabalho com a teoria de Marshall Sahlins explicitada em seu livro intitulado Ilhas de História (1990). Neste livro, Sahlins discute a questão de que culturas distintas, diante de um mesmo evento fariam interpretações distintas deste evento. Tais interpretações estariam ligadas às diferentes formas de compreensão da história. Para Sahlins, não existe uma história objetiva que esteja situada num patamar além das culturas. Ao invés disso, o que existe são diferentes histórias que estão ligadas a diferentes culturas.
A história é ordenada culturalmente de diferentes modos nas diversas sociedades, de acordo com os esquemas de significação das coisas. $\mathrm{O}$ contrário também é verdadeiro: esquemas culturais são ordenados historicamente porque, em maior ou menor grau, os significados são reavaliados quando realizados na prática. A síntese desses contrários desdobra-se nas ações criativas dos sujeitos históricos, ou seja, as pessoas envolvidas. Porque, por um lado, as pessoas organizam seus projetos e dão sentido aos objetos partindo das compreensões preexistentes da ordem cultural. (SAHLINS, 1990: 7)

A partir desta visão de história, podemos começar a entender as razões existentes por trás das diferentes interpretações tanto da pequena ruína da terra indígena Tavaí, das ruínas jesuíticas na região das missões e da fortaleza de São José de Macapá. Estas três marcas materiais inseridas em suas respectivas paisagens são pontos focais de diálogo e tensão a respeito das interpretações históricas possíveis destes lugares. 
Trabalho com a ideia de que há uma forte ligação entre eventos históricos e/ou eventos mitológicos e as marcas materiais que tais eventos deixaram na paisagem. Portanto, pode-se dizer que trabalho com a materialidade dos eventos "mito-históricos". Esta ligação entre materialidade e eventos "mito-históricos" coloca esta abordagem num ponto de contato entre a antropologia, a história e a arqueologia.

\section{CUTURAS DISTINTAS, HISTORICIDADES DISTINTAS}

Marshall Sahlins argumenta que há basicamente dois tipos de estruturas de entendimento histórico. Há culturas que se fundamentam em estruturas prescritivas que se caracterizam por adaptarem os eventos históricos à uma ordem culturalmente preestabelecida. Desta forma, todo evento já está previsto no corpus mitológico que funciona como alicerce das estruturas prescritivas. Em tais culturas, passado, presente e futuro já estão estabelecidos, bastando apenas às pessoas encaixarem os eventos na estrutura.

Já as culturas que possuem uma estrutura performativa são aquelas onde os eventos não precisam se encaixar numa ordem preestabelecida. Os eventos não precisam estar previstos para poderem ser interpretados. Desta forma, os eventos não possuem nenhuma ligação necessária com o passado mítico, podendo ser eventos completamente novos que, para serem compreendidos, necessitarão de uma abordagem mais centrada neles próprios e não em ligações com eventos passados. Exemplos típicos de sociedades que possuem esta forma de estrutura são as ocidentais, que desenvolveram interpretações históricas onde é mais evidente o papel da inovação, ao contrário de outras sociedades que desenvolveram interpretações históricas onde a repetição cíclica é o elemento preponderante.

Entretanto, Sahlins defende que dentro de uma mesma cultura podem existir pontos onde funcionam estruturas diferentes. Assim, uma sociedade que possua, de modo geral, uma estrutura prescritiva, pode possuir certos aspectos onde funcionem uma estrutura performativa:

(...) estruturas performativas e prescritivas são tipos ideais. As duas podem ser encontradas na mesma sociedade, em vários locais da ordem global. Isso também implica que, em uma dada sociedade, existirão certos pontos estratégicos de ação histórica, áreas circunstancialmente quentes, e outras relativamente fechadas.

(SAHLINS, 1990: 14)

No caso específico aqui analisado, percebe-se que a pequena ruína presente na TekoáTavaí congrega tanto a estrutura performativa (modo pelo qual a historicidade ocidental Ihe interpreta como sendo palco de um evento relacionado à conturbada história da revolução 
farroupilha e de um de seus personagens mais importantes e emblemáticos: o general Bento Gonçalves) e a estrutura prescritiva (a integração da ruína à tradição oral Mbyá-Guarani e sua interpretação mítica relacionada aos ancestrais que nela realizaram seus ritos e fizeram suas rezas). Portanto, pode-se dizer que a pequena ruína da TekoáTavaíe a paisagem em que está inserida constituem-se em áreas de diálogo e tensão entre sociedades distintas e suas respectivas estruturas de entendimento histórico. Ela serve tanto para a construção da identidade cívica gaúcha quanto para a construção da identidade étnicaMbyá-Guarani. Neste caso, mais uma vez gostaríamos de lembrar Marshall Sahlins.

Um evento transforma-se naquilo que lhe é dado como interpretação. Somente quando apropriado por, e através do esquema cultural, é que adquire uma significância histórica. (SAHLINS, 1990: 15)

\section{PAISAGEM, MITOLOGIA E ETNICIDADE}

Os eventos históricos acontecem em lugares definidos e, desta forma, podem ser localizados geograficamente, o que constitui uma importante ferramenta para a construção de historicidades e etnicidades. O parque histórico general Bento Gonçalves não teria a mesma eficácia como símbolo identitário caso não houvesse em sua área nada que remetesse à história do general que lhe dá nome. Teria um efeito menor construir um parque em homenagem à revolução farroupilha ao redor da fortaleza de São José de Macapá pela simples razão de que o Amapá estáhá milhares de quilômetros distantes dos eventos desta revolução. Portanto, os lugares estão ligados aos eventos, potencializando seus significados simbólicos. Umapessoa que não conhecesse a história ou os mitos de um determinado lugar poderia se locomover por uma pelapaisagem sem reconhecer nela nada que fosse importante para os habitantes nativos que, ao contrário desta pessoa,por conhecerem os eventos ocorridos napaisagem poderiam distinguir nela lugares importantes carregados de intensa carga histórica e/ou mitológica. Isso mostra que conhecer os eventos históricos e/ou mitológicos que ocorreram numa paisagem significa possuir um conhecimento da própria paisagem. Tim Ingold aborda esta questão ao mostrar as ligações entre lugares e suas histórias e como lugares unidos por itinerários de seres humanos, espíritos, divindades, etc., formam algo que ele denomina região.

De fato, habitantes nativos podem não conseguir determinar seu lugar no espaço de acordo com algum sistema independente de coordenadas, insistindo todavia, com razão, que sabem onde estão. Isso, como mostrarei, ocorre porque os lugares não têm posições e sim 
histórias. Unidos pelos itinerários de seus habitantes, os lugares existem não no espaço, mas, como nós, em uma matriz de movimento. Chamarei essa matriz de "região". É o conhecimento da região, e com isso a habilidade de uma pessoa situar-se na sua posição atual dentro do contexto histórico de jornadas efetuadas anteriormente - jornadas para lugares, de lugares e em volta de lugares - que distingue o nativo do forasteiro. Assim, descobrir- caminho comum assemelha-se mais a contar histórias do que utilizar um mapa. (INGOLD, 2005: 219)

Os Mbyá-Guarani possuem uma forte ligação com seu território tradicional. Esta ligação vai muito além da simples presença de recursos ambientais importantes para a manutenção econômica deste grupo indígena. Os Mbyá-Guarani reconhecem em seu território tradicional as marcas deixadas por suas divindades e seus heróis míticos, assim como por seus ancestrais históricos. Portanto, a região (tal como a define Ingold no trecho acima) MbyáGuarani é aquela que abrange seus itinerários geográficos e históricos, além dos itinerários de seus heróis míticos. Portanto, concentra-se, na pequena ruína que denomina a TekoáTavaí, o ponto de encontro de mitologia, paisagem e etnicidade. O mesmo pode ser dito a respeito dos gaúchos que, na mesma pequena ruína, veem o ponto de encontro de história, paisagem e identidade cívica.

\section{CONSIDERAÇÕES FINAIS}

Toda paisagem constitui um palimpsesto seja numa perspectiva diacrônica, seja numa perspectiva sincrônica. Em alguns lugares, tais como o da pequena ruína que pertence, simultaneamente, ao parque histórico Bento Gonçalves e à TekoáTavaí, as duas perspectivas estão presentes. Os doisgrupos se sentem representados pela mesma ruína, mas não pela mesma narrativa que é contada sobre ela. Se comparássemos a ruína a um suporte material que servisse para se transmitir uma mensagem, tal como o papel ou mesmo o suporte rochoso onde se pode produzir arte rupestre, veríamos que sobre ele está inscrito dois sistemas de signos, dois modelos de representação, dois universos simbólicos. Entretanto, a coexistência de símbolos de culturas diferentes num mesmosuporte não parece afetar negativamente a nenhum dos lados envolvidos. Os visitantes e turistas não-indígenas que visitam o parque histórico Bento Gonçalves e que estacionam seus carros, preparam seus churrascos e até montam suas barracas bem próximo da pequena ruína não parecem se incomodar com a presença Mbyá, assim como os Mbyá não parecem se incomodar com os visitantes desde que estes respeitem certos limites territoriais. Não foi observado nenhuma 
disputa sobre qual seria a interpretação "correta" da pequena ruína. Para os visitantes nãoíndígenas, ela continua sendo o símbolo cívico ligado à revolução farroupilha. Para os Mbyá, ela continua sendo o símbolo religioso da antiga casa de reza de seus ancestrais (opy).

\section{Agradecimentos}

Agradeço à CAPES pela bolsa de estudos que tornou possível realizar a pesquisa na TekoáTavaí.

\section{REFERÊNCIAS BIBLIOGRÁFICAS}

BASTIAN. D. E. e MITCHELL. J. K. HandbookofNative American Mythology. Santa Bárbara, EUA: ABC-CLIO. 2004. 313 p.

GEERTZ. C. A Religião Como Sistema Cultural. In A Interpretação das Culturas. Rio de Janeiro. LTC Editora, 1989. P. $65-91$.

GALLOIS. D. T. Mairi Revisitada: A Reintegração da Fortaleza de Macapá na Tradição Oral dos Waiãpi. São Paulo. Núcleo de História Indígena e Indigenismo - USP. 1994.

INGOLD, T. Jornada ao longo de um caminho de vida - mapas, descoberta-de-caminho e navegação. In Religião e Sociedade, Rio de Janeiro, 2005. p. 219 - 242.

LITAIFF. A. As Divinas Palavras: Identidade Étnica dos Guarani-Mbyá. Editora da UFSC. Florianópolis, 1996. $160 \mathrm{p}$.

. "Kesuita" Guarani: Mitologia e Territorialidade. RevistaEspaço Ameríndio UFRGS, Porto Alegre, v. 3, n. 2, p. 142-160, jul./dez. 2009.

SAHLINS. M. Ilhas de História. Rio de Janeiro. Ed. Jorge Zahar. 1990. 217 p.

\begin{tabular}{|l|l|l|l|l|l|l}
\hline (C Rev. Arqueologia Pública & Campinas, SP & v.9 & No.(11) & p.157-166 & suplemento & ISSN 2237-8294 \\
\hline
\end{tabular}

